\title{
Synthesis and Characterization of a New Polytriazole Resin Derived from $N, N$-Dipropargyl-p-propargyloxyaniline
}

\author{
By Xiaofei WANG, ${ }^{1}$ Zhanfeng ZHAO, ${ }^{1}$ Jianjun TIAN, ${ }^{1}$ Liqiang $W A N,{ }^{1}$ \\ Yanhong $H U,{ }^{1}$ Farong HUANG, ${ }^{1, *}$ and Lei DU ${ }^{2}$
}

$N, N$-Dipropargyl-p-propargyloxyaniline (DPPA) was synthesized and characterized. A new polytriazole (PTA) resin was prepared from DPPA and 1,3,5-tris(azidomethyl)-2, 4, 6-trimethyl-benzene (TAMTMB). The physical properties, rheological behavior, curing behavior, thermal and mechanical properties of the PTA resin were investigated. The results showed that the PTA resin could cure initially at $70^{\circ} \mathrm{C}$ and completely at $200^{\circ} \mathrm{C}$. The cured PTA resin had good heat resistance and high mechanical properties.

KEY WORDS: $N, N$-Dipropargyl-p-propargyloxyaniline / 1, 3-Dipolar Cycloaddition / Polytriazole Resin / Curable Resin Matrix at Low

Temperature for Advanced Composites /

There has been a steady growth of interest in Huisgen 1, 3dipolar cycloaddition reaction between azide and alkyne groups. The cycloaddition results in the formation of 1,2,3triazole heterocycle and has been used as a universal ligation tool in polymer and material science. ${ }^{1-6}$ The Huisgen reaction of azide and alkyne compounds always takes place at a low temperature (lower than $100^{\circ} \mathrm{C}$ ), and produces mixtures of 1, 4- and 1, 5-regioisomers (Scheme 1) without a catalyst, showing the possibility of developing a curable resin at low temperature from multifunctional azides and alkynes.

In 1960s, K. E. Johson et al. synthesized several compounds containing both azide and alkyne groups and found that the polymer produced from $p$-azidophenyl acetylene at $60^{\circ} \mathrm{C}$ exhibited good thermal properties but poor processability. ${ }^{7,8}$ Recently, our team has been developing a series of polytriazole (PTA) resins with low temperature curing character, good processability, good mechanical and thermal properties by introducing $-\mathrm{CH}_{2}-,-\mathrm{O}-$, etc. flexible groups into main aromatic chains. The PTA resins are promising advanced thermosetting resins. ${ }^{9-14}$

Although a cured PTA resin (PTA-34) with $T_{\mathrm{g}}$ of $324^{\circ} \mathrm{C}$ had been prepared, ${ }^{12}$ it showed a little bit brittleness and poor mechanical properties because of high crosslinking density. Herein, a new trialkyne compound, $N, N$-dipropargyl-p-propargyloxyaniline (DPPA), was designed and synthesized. And further a new PTA resin was prepared from DPPA and 1, 3, 5tris(azidomethyl)-2, 4, 6-trimethyl-benzene (TAMTMB). The physical properties, rheological behavior, curing behavior, thermal and mechanical properties of the PTA resin were investigated.

\section{EXPERIMENTAL}

\section{Raw Materials}

$p$-Aminophenol (industrial purity, recrystallized before use,
Anhui Bayi Chemical Industry Co. Ltd), propargyl bromide (industrial purity, distilled before use, Shanghai Bangcheng Chemical Co. Ltd), potassium carbonate, 1,2-dichloroethane, benzyltriethylammonium chloride, $n$-hexane, $n$-butanol (all analytical reagents, Sinopharm Chemical Reagent Co. Ltd), etc. were used for the synthesis of DPPA.

\section{Instrumentation}

Proton Nuclear Magnetic Resonance $\left({ }^{1} \mathrm{H}\right.$ NMR) spectra were obtained from a BRUKER AVANCE $500(500 \mathrm{Mz})$ instrument, and tetramethylsilane (TMS) was used as an internal standard. Fourier Transform Infrared (FT-IR) spectra were recorded on a Nicolet 550 instrument (TA, U.S.) and the sample powder was pressed into a pellet with $\mathrm{KBr}$. Rheological behavior was traced on a RheoStress RS600 Rheometer with the heating rate of $2{ }^{\circ} \mathrm{C} / \mathrm{min}$ which was carried out on a plate and the shear rate of $0.01 \mathrm{~S}^{-1}$ in temperature range from $30^{\circ} \mathrm{C}$ to $120^{\circ} \mathrm{C}$. Differential Scanning Calorimetry (DSC) analysis was carried out on the Diamond DSC (PE, U.S.) analyser under nitrogen at the heating rate of $10^{\circ} \mathrm{C} / \mathrm{min}$. Dynamic Mechanical Analysis (DMA) was carried out on the Rheogel-E4000 (UBM, Japan) analyser operating in a tension mode under nitrogen at the frequency of $11 \mathrm{~Hz}$ with a programmed heating rate of $3{ }^{\circ} \mathrm{C} / \mathrm{min}$. Thermogravimetry Analysis (TGA) was conducted on the Pyris Diamond TG/DTA (PE, U.S.) at the heating rate of $10^{\circ} \mathrm{C} / \mathrm{min}$. The mechanical property of the cured resin was measured with Sans AG-2000A electronic universal testing machine (MTS System (CHINA) Co., Ltd.) at the loading rate of $2 \mathrm{~mm} / \mathrm{min}$.

\section{Synthesis of DPPA and TAMTMB Monomers}

DPPA was first synthesized as a pesticide by a solution method in $1966,{ }^{15}$ but not clearly characterized. Herein, we synthesized DPPA by phase transfer catalysis (Scheme 2).

\footnotetext{
${ }^{1}$ Key Laboratory for Specially Functional Polymeric Materials and Related Technology of the Ministry of Education, School of Materials Science and Engineering, East China University of Science and Technology, Shanghai 200237, P. R. China

${ }^{2}$ Shanghai Bureau of Astronautics, Shanghai 200233, P. R. China

*To whom correspondence should be addressed (Tel: +86-21-6425-1110(O), Fax: +86-21-6425-3031, E-mail: fhuanglab@ecust.edu.cn).
} 


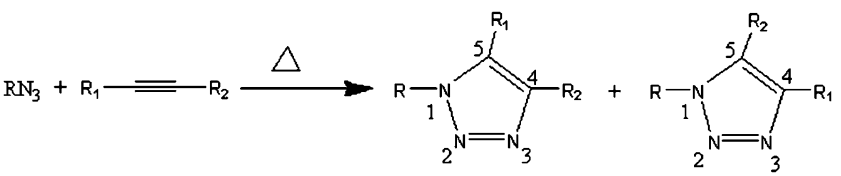

Scheme 1. Huisgen 1, 3-dipolar cycloaddition reaction of azides and alkynes.

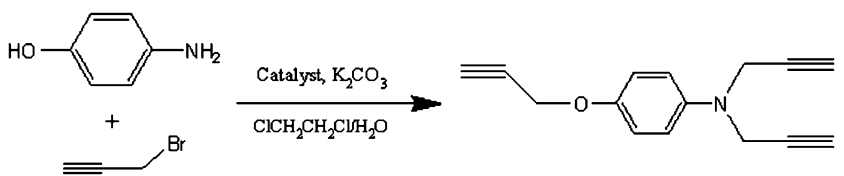

Scheme 2. Synthetic route of DPPA.

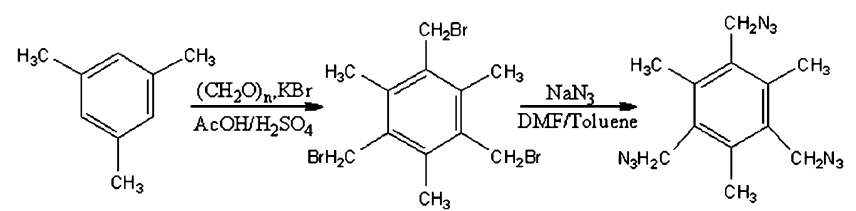

Scheme 3. Synthesis of TAMTMB.

In a $250 \mathrm{~mL}$ flask equiped with a gas inlet, a condenser, a stirrer and a dropping funnel, $17.44 \mathrm{~g}(0.16 \mathrm{~mol}) \mathrm{p}$-aminophneol, $33.12 \mathrm{~g}(0.24 \mathrm{~mol})$ potassium carbonate, $1.60 \mathrm{~g}$ $(0.007 \mathrm{~mol})$ benzyltriethylammonium chloride, $40 \mathrm{~mL} 1,2-$ dichloroethane and $50 \mathrm{~mL}$ deionized water were added and stirred at room temperature. After the mixture was heated to $70{ }^{\circ} \mathrm{C}, 57.12 \mathrm{~g}(0.48 \mathrm{~mol})$ propargyl bromide was added dropwise to the mixture. The dropping operation continued for $1 \mathrm{~h}$, and then the flask was maintained at $70^{\circ} \mathrm{C}$ for $6 \mathrm{~h}$ under nitrogen. The reaction mixture was allowed to cool down to room temperature, and washed with deionized water several times. The organic layer was collected and concentrated by distillation. Thereafter the crude product was extracted with $n$ hexane at $70^{\circ} \mathrm{C}$. Yellow solid product was crystallized when the $n$-hexane solution was cooling down to $5^{\circ} \mathrm{C}$. Then the solid was recrystallized from $n$-butanol two times and finally a light yellow solid product was obtained. Yield: $51 \%$, purity: $98.7 \%$ (HPLC), mp: $37-38{ }^{\circ} \mathrm{C} .{ }^{1} \mathrm{H}$ NMR $\left(\mathrm{CDCl}_{3}, \mathrm{TMS}\right) \delta: 6.96(\mathrm{~m}$, $4 \mathrm{H},-\mathrm{Ar}-\mathrm{H}), 4.65$ (d, 2H, -O-CH $\left.2^{-}\right), 4.05$ (d, 4H, -N-CH $\left.2^{-}\right), 2.50$ (tr, $1 \mathrm{H},-\mathrm{O}-\mathrm{R}-\mathrm{C} \equiv \mathrm{CH}), 2.25(\mathrm{tr}, 2 \mathrm{H},-\mathrm{N}-\mathrm{R}-\mathrm{C} \equiv \mathrm{CH}) . \mathrm{FT}-\mathrm{IR}(\mathrm{KBr}$, $\left.v, \mathrm{~cm}^{-1}\right): 3290(\equiv \mathrm{C}-\mathrm{H}), 2120(-\mathrm{C} \equiv \mathrm{C}-), 1225$ and 1030 (C-OC). Elemental analysis for $\mathrm{C}_{15} \mathrm{H}_{13} \mathrm{NO}$, Found (Calcd) (\%): $\mathrm{C}$ 80.48 (80.69), H 5.35 (5.67), N 6.17 (6.27).

1, 3, 5-tris(azidomethyl)-2, 4, 6-trimethyl-benzene (TAMTMB) was synthesized in two steps by azide substitution of 1, 3, 5tris(bromomethyl)-2, 4, 6-trimethyl-benzene, followed by bromomethylation of mesitylene (Scheme 3) according to the literatures. $^{12,13}$ The yield of TAMTMB was 58\%, mp: 60 $62{ }^{\circ} \mathrm{C} .{ }^{1} \mathrm{H}$ NMR $\left(\mathrm{CDCl}_{3}, \mathrm{TMS}\right) \delta: 4.50\left(\mathrm{~s}, 6 \mathrm{H}, \mathrm{CH}_{2}\right), 2.45(\mathrm{~s}$, $\left.9 \mathrm{H}, \mathrm{CH}_{3}\right)$. FT-IR $\left(\mathrm{KBr}, v, \mathrm{~cm}^{-1}\right): 2089\left(-\mathrm{N}_{3}\right)$.

\section{Preparation of a Polytriazole Resin}

DPPA and TAMTMB were well proportioned (the molar<smiles>C=CC(C=C)C(C)CCCCC(CN)CN</smiles>

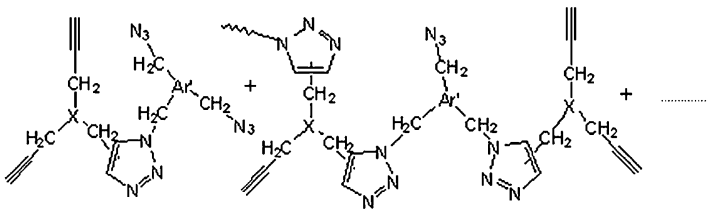

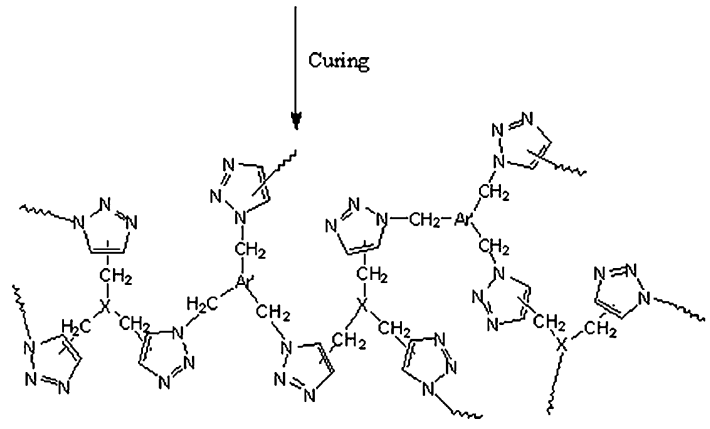

$$
\mathrm{x}=-\mathrm{O} \mathrm{N}_{\mathrm{\prime}}^{\prime}
$$

Scheme 4. Curing reactions and crosslinked network structure of the PTA resin.

ratio of alkyne to azide group 1.0:1.0) and mixed by stirring at $70{ }^{\circ} \mathrm{C}$ (about $10 \mathrm{~min}$ ) till a homogeneous liquid occurred. Thus a polytriazole (PTA) resin was obtained (Scheme 4).

\section{Preparation of PTA Resin Castings for the Compressive Test and Thermal Analysis}

The obtained polytriazole resin was poured into a cylinder mold. Then the resin with the mold was together put into a vacuum oven for removing air embedded. Thereafter, the mold was transferred into an other oven for being cured at $70^{\circ} \mathrm{C}$ for $12 \mathrm{~h}$. The cured resin samples were demolded and were postcured on the following procedure: $110^{\circ} \mathrm{C} / 2 \mathrm{~h}+150^{\circ} \mathrm{C} /$ $2 \mathrm{~h}+180^{\circ} \mathrm{C} / 2 \mathrm{~h}+200^{\circ} \mathrm{C} / 2 \mathrm{~h}$. The size of the cylinder casting samples for compressive test was $\phi 7.0 \times 30.0 \mathrm{~mm}^{2}$. The cured resin samples for thermal analysis were obtained in similar curing procedure above.

\section{RESULTS AND DISCUSSION}

\section{Physical Properties of the PTA Resin}

The PTA resin made from DPPA and TAMTMB was a light yellow liquid at $70^{\circ} \mathrm{C}$ and faint yellow solid at ambient temperature, and its solubility was tested in some common solvents such as toluene, chloroform, acetone, THF and $N, N$ dimethyl formamide etc. at room temperature. The results were tabulated in the Table I. As shown in Table I, the PTA resin 
Table I. Solubility of the PTA resin in common solvents at ambient temperature

\begin{tabular}{|c|c|c|c|c|c|c|c|c|}
\hline Solvent & Toluene & Acetone & Butanone & DMF & DMAC & Methanol & Ethanol & Butanol \\
\hline Solubility & + & + & + & + & + & + & + & \pm \\
\hline Solvent & Isopropanol & THF & Dioxane & $\begin{array}{l}\text { Dichloro- } \\
\text { methane }\end{array}$ & Chloroform & Ether & Hexane & \\
\hline Solubility & \pm & + & + & + & + & \pm & - & \\
\hline
\end{tabular}

+: Soluble \pm : Partially soluble -: Insoluble.

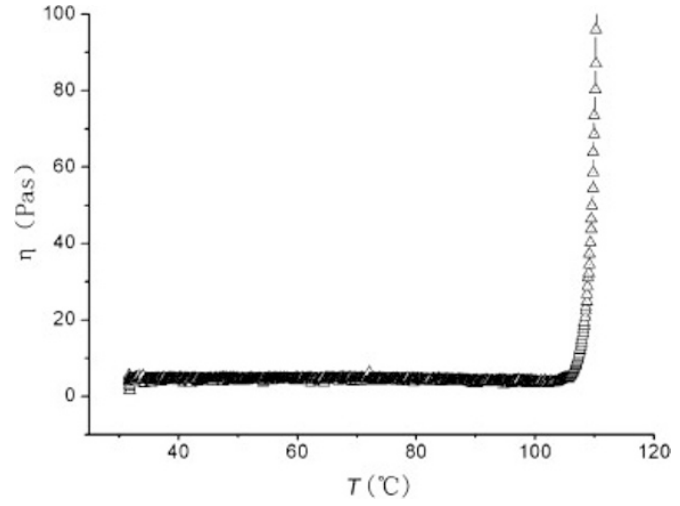

Figure 1. Viscosity-temperature curve of the PTA resin (heating rate $2{ }^{\circ} \mathrm{C} /$ $\min )$.

exhibited good solubility in most of common solvents at ambient temperature.

\section{Rheological Behavior of the PTA Resin}

The viscosity response to temperature ramping at a heating rate of $2{ }^{\circ} \mathrm{C} / \mathrm{min}$ by rheometer analysis was shown in Figure 1 . As shown in Figure 1, the viscosity of the resin maintained a low value (less than $5 \mathrm{~Pa} \cdot \mathrm{s}$ ) in the temperature range of ambient temperature to $105^{\circ} \mathrm{C}$. At a temperature above $105^{\circ} \mathrm{C}$, the viscosity increased rapidly, which indicated that the gelation of the resin occurred. These results demonstrated that the PTA resin had good processability.

\section{The Curing of the PTA Resin}

Figure 2 presented DSC trace of the PTA resin under nitrogen at a heating rate of $10^{\circ} \mathrm{C} / \mathrm{min}$. As shown in Figure 2, the endothermic peak in the range of $30^{\circ} \mathrm{C}$ to $60^{\circ} \mathrm{C}$ was due to the melting of the resin. It was observed that the PTA resin showed a large unimodal exotherm peak in the range of $70^{\circ} \mathrm{C}$ to $200{ }^{\circ} \mathrm{C}$, attributed to the cycloaddition reactions of alkyne and azide groups. The total exothermic reaction heat of the PTA resin was $1112 \mathrm{Jg}^{-1}$, which was much higher than that of conventional thermosetting resins such as benzoxazine ${ }^{16}$ and bismaleimide resin. ${ }^{17} \mathrm{~A}$ small peak occurred in the range of 200 to $270^{\circ} \mathrm{C}$, which may be due to the reactions of the residual functional groups under the testing conditions.

The changes of the characteristic functional groups of PTA resin in the curing process were traced by FT-IR technique, as shown in Figure 3. Absorption intensity of $\equiv \mathrm{CH}\left(3290 \mathrm{~cm}^{-1}\right)$, $-\mathrm{N}_{3}$ and $\mathrm{C} \equiv \mathrm{C}\left(2100 \mathrm{~cm}^{-1}\right)$ groups decreased gradually with the

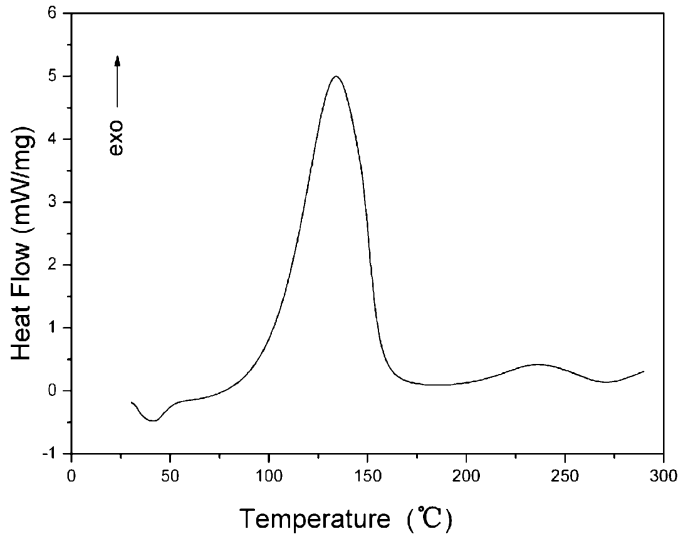

Figure 2. DSC curve of the PTA resin (heating rate $10^{\circ} \mathrm{C} / \mathrm{min}$, nitrogen).

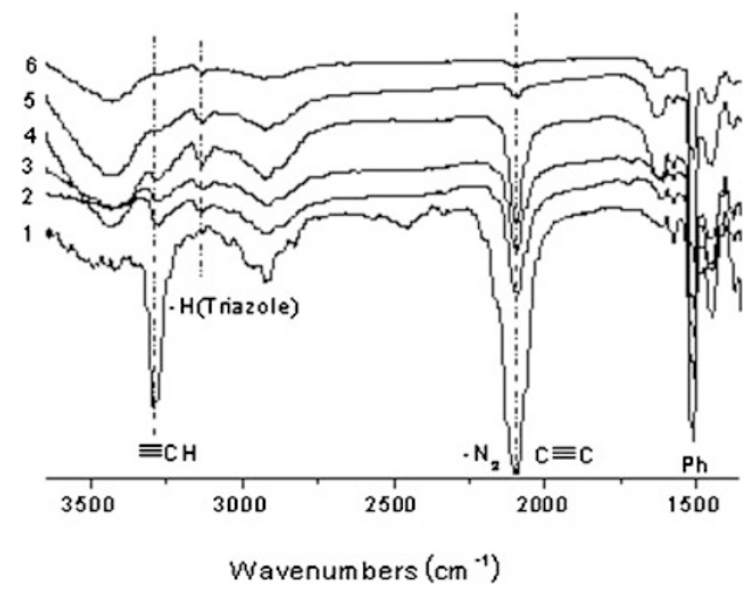

Figure 3. IR spectra of the PTA resin at different curing stages.

curing temperature and time increasing while the peaks at $3134 \mathrm{~cm}^{-1}$ for the characteristic absorption of $\mathrm{C}-\mathrm{H}$ on the triazole ring occurred and enhanced, which indicated that the cycloaddition reactions between azide and alkyne groups had taken place and 1, 2, 3-triazole heterocycles had formed. After the PTA resin was cured at $70^{\circ} \mathrm{C} / 12 \mathrm{~h}+110^{\circ} \mathrm{C} / 2 \mathrm{~h}+$ $150{ }^{\circ} \mathrm{C} / 2 \mathrm{~h}+180{ }^{\circ} \mathrm{C} / 2 \mathrm{~h}+200^{\circ} \mathrm{C} / 2 \mathrm{~h}$, the absorption peaks of $\equiv \mathrm{CH} \quad\left(3290 \mathrm{~cm}^{-1}\right),-\mathrm{N}_{3}$ and $\mathrm{C} \equiv \mathrm{C}\left(2100 \mathrm{~cm}^{-1}\right)$ totally disappeared, which illustrated that the curing reactions of the PTA resin had been completed. The curing reactions and crosslinked structure of the PTA resin was shown in Scheme 4.

The curing degrees of the PTA resin at different curing stages were obtained by calculating the ratio of area of the peak 
Table II. Curing degrees of the PTA resin at different curing stages by FT-IR measurement

\begin{tabular}{lcc}
\hline \multicolumn{1}{c}{ Curing stage } & \multicolumn{2}{c}{ Curing degree (\%) } \\
\cline { 2 - 3 } & A & B \\
\hline $70^{\circ} \mathrm{C} / 12 \mathrm{~h}$ & 73.1 & 70.3 \\
$70^{\circ} \mathrm{C} / 12 \mathrm{~h}+110^{\circ} \mathrm{C} / 2 \mathrm{~h}$ & 81.7 & 77.6 \\
$70^{\circ} \mathrm{C} / 12 \mathrm{~h}+110^{\circ} \mathrm{C} / 2 \mathrm{~h}+150^{\circ} \mathrm{C} / 2 \mathrm{~h}$ & 91.9 & 86.7 \\
$70^{\circ} \mathrm{C} / 12 \mathrm{~h}+110^{\circ} \mathrm{C} / 2 \mathrm{~h}+150^{\circ} \mathrm{C} / 2 \mathrm{~h}+180^{\circ} \mathrm{C} / 2 \mathrm{~h}$ & 99.8 & 98.1 \\
$70^{\circ} \mathrm{C} / 12 \mathrm{~h}+110^{\circ} \mathrm{C} / 2 \mathrm{~h}+150^{\circ} \mathrm{C} / 2 \mathrm{~h}+180^{\circ} \mathrm{C} / 2 \mathrm{~h}+200^{\circ} \mathrm{C} / 2 \mathrm{~h}$ & 99.8 & 98.1
\end{tabular}

A: based on the peak at $3290 \mathrm{~cm}^{-1}$; B: based on the peak at $2100 \mathrm{~cm}^{-1}$.

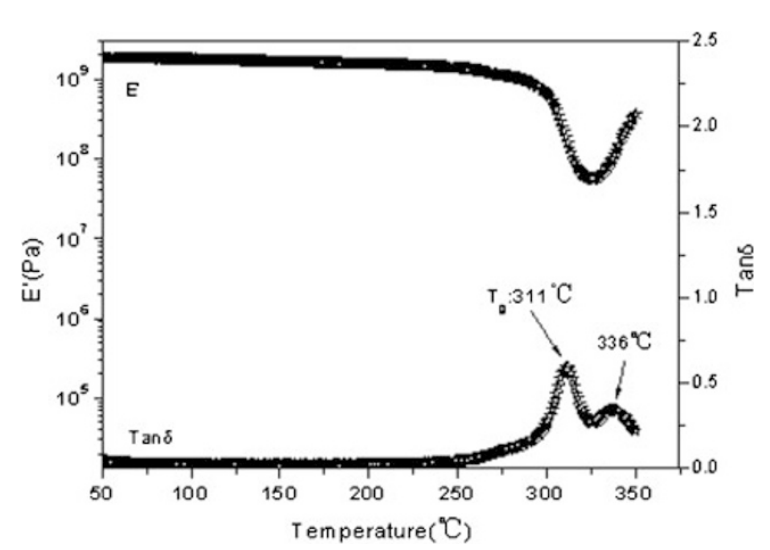

Figure 4. The storage modulus $\left(E^{\prime}\right)$ and $\operatorname{Tan} \delta$ as a function of temperature for the cured PTA resin (heating rate $3^{\circ} \mathrm{C} / \mathrm{min}$, nitrogen, $11 \mathrm{~Hz}$ ).

at $3290 \mathrm{~cm}^{-1}$ or $2100 \mathrm{~cm}^{-1}$ to that at $1510 \mathrm{~cm}^{-1}$ (benzene ring as an internal standard). The results were listed in Table II. As shown in Table II, curing degrees changed with the curing temperature and time. The curing degrees based on the peak at $3290 \mathrm{~cm}^{-1}$ corresponded with those on the peak at $2100 \mathrm{~cm}^{-1}$ even though there existed slight difference. The curing degree of the PTA resin reached about $99 \%$ after the resin was cured at $70{ }^{\circ} \mathrm{C} / 12 \mathrm{~h}+110^{\circ} \mathrm{C} / 2 \mathrm{~h}+150^{\circ} \mathrm{C} / 2 \mathrm{~h}+180^{\circ} \mathrm{C} / 2 \mathrm{~h}$. While the resin was cured at $70^{\circ} \mathrm{C} / 12 \mathrm{~h}+110^{\circ} \mathrm{C} / 2 \mathrm{~h}+150^{\circ} \mathrm{C} /$ $2 \mathrm{~h}+180^{\circ} \mathrm{C} / 2 \mathrm{~h}+200^{\circ} \mathrm{C} / 2 \mathrm{~h}$, the curing degree of the PTA resin maintained the same, indicating that the curing of the PTA resin had been completed.

\section{The Thermal Properties of the Cured PTA Resin}

Dynamic Mechanical Analysis (DMA) of the cured PTA resin was carried out under nitrogen atmosphere and DMA traces were shown in Figure 4. As shown in Figure 4, the storage modulus, $E^{\prime}$, decreased sharply at $c a .300^{\circ} \mathrm{C}$, and the maximum of $\tan \delta$ peak occurred, i.e., the glass transition temperature of the cured resin reached $311^{\circ} \mathrm{C}$, which was much higher than those of other PTA resins (PTA-24, $T_{\mathrm{g}}$, $218^{\circ} \mathrm{C}, 250^{\circ} \mathrm{C}$ ) made from diazide and tetraalkyne, ${ }^{10,11}$ but lower than that of PTA-34 prepared from triazide and tetraalkyne. This indicated that the functionality of the monomer influenced the glass transition temperature of the resin. The increase of the storage modulus at $c a .325^{\circ} \mathrm{C}$ and a small $\tan \delta$ peak at $336^{\circ} \mathrm{C}$ were possibly attributed to the
Table III. Compressive properties of the cured PTA resin at ambient temperature

\begin{tabular}{cccc}
\hline Resin sample & $\begin{array}{c}\text { Compressive } \\
\text { strength } \\
(\mathrm{MPa})\end{array}$ & $\begin{array}{c}\text { Compressive } \\
\text { modulus } \\
(\mathrm{GPa})\end{array}$ & $\begin{array}{c}\text { Compressive } \\
\text { strain } \\
(\%)\end{array}$ \\
\hline PTA Resin & $208.6 \pm 4.4$ & $3.4 \pm 0.2$ & 11.2 \\
PTA-34 ${ }^{12}$ & $194.9 \pm 1.1$ & $3.5 \pm 0.1$ & 9.5 \\
\hline
\end{tabular}

thermal degradation of the cured resin, which would be confirmed by the thermogravimetric analysis.

\section{The Mechanical Properties of the Cured PTA Resin}

The compressive properties of the cured PTA resin at ambient temperature were measured and the results were listed in Table III. As shown in Table III, the cured PTA resin had a higher compressive strength (208.6 MPa) and a little lower compressive modulus $(3.4 \mathrm{GPa})$ as compared with PTA-34. Especially, the compressive strain of the cured PTA resin reached $11.2 \%$, indicating that the cured PTA resin had higher toughness than PTA-34. Therefore the cured PTA resin possessed good mechanical properties.

\section{The Thermal Stability of the Cured PTA Resin}

Thermal stability of the cured PTA resin was investigated by TGA. The TGA profiles of the cured PTA resin under nitrogen and air atmosphere were shown in Figure 5, which indicated that the degradation temperature $T_{\mathrm{d} 5}$ (the temperature of degradation at 5\% weight loss) for the cured PTA resin under nitrogen and air were 333 and $339^{\circ} \mathrm{C}$. The char yield of the cured PTA resin at $800^{\circ} \mathrm{C}$ under nitrogen was $41 \%$, while $1 \%$ under air, which reflected that the oxygen took part in the thermal degradation under air atmosphere. Another noticeable feature was that the degradation of the cured PTA resin under nitrogen occurred through one step, while that under air through two steps. As shown in Figure 5, the two curves were almost overlapped in the range of RT to $c a .550{ }^{\circ} \mathrm{C}$, which indicated that there was the same degradation behavior in this temperature range. The degradation would initiate at the cleavage of the weak bonds $\mathrm{H}_{2} \mathrm{C}-\mathrm{N} .{ }^{18}$ However, when the temperature was at higher than $550{ }^{\circ} \mathrm{C}$ under air, thermal oxidative degradation might be the main process. These TGA results indicated the cured PTA resin performed excellent thermal stability. 


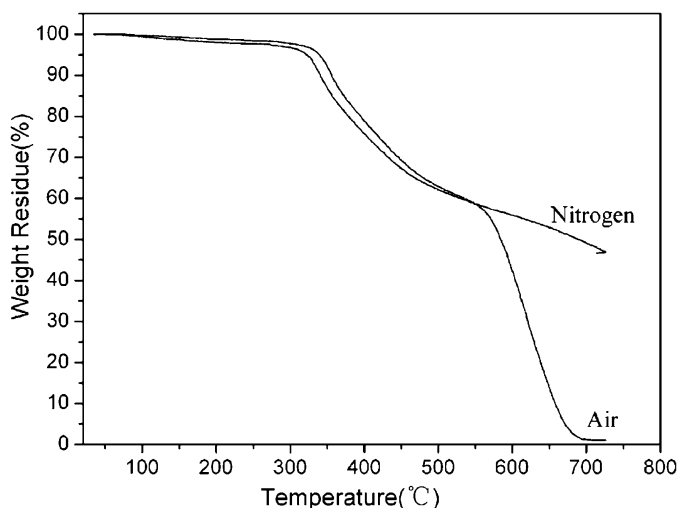

Figure 5. TGA curves of the cured PTA resin under nitrogen and air a heating rate of $10^{\circ} \mathrm{C} / \mathrm{min}$.

\section{CONCLUSIONS}

$N, N$-Dipropargyl-p-propargyloxyaniline (DPPA) was synthesized and characterized. A new polytriazole resin was prepared from DPPA and 1, 3, 5-tris(azidomethyl)-2, 4, 6-trimethylbenzene (TAMTMB). The PTA resin exhibited good solubility in common solvents at ambient temperature. Viscosity-temperature curve showed good processability of the PTA resin. DSC result indicated the PTA resin could cure at the temperature range of 70 to $200{ }^{\circ} \mathrm{C}$. IR spectra showed the curing degree of the PTA resin reached $99 \%$ when cured at $70^{\circ} \mathrm{C} /$ $12 \mathrm{~h}+110^{\circ} \mathrm{C} / 2 \mathrm{~h}+150{ }^{\circ} \mathrm{C} / 2 \mathrm{~h}+180^{\circ} \mathrm{C} / 2 \mathrm{~h}+200^{\circ} \mathrm{C} / 2 \mathrm{~h}$. The $T_{\mathrm{g}}$ of the cured PTA resin reached $311^{\circ} \mathrm{C}$. Thermal degradation temperature $T_{\mathrm{d} 5}$ of the cured PTA resin reached $333^{\circ} \mathrm{C}$ (nitrogen) and $339^{\circ} \mathrm{C}$ (air). The compressive strength and modulus of the cured PTA resin arrived at $208.6 \mathrm{MPa}$ and $3.4 \mathrm{GPa}$, respectively. The PTA resin was a promising resin matrix with low temperature curable characteristics for advanced composites.

Acknowledgment. The authors gratefully acknowledge the financial support of the National High Technology Research and Development Program of China (Grant No. 2002A305103) and the National Basic Research Program of China (Grant No. 5131101).

Received: December 6, 2008 Accepted: March 8, 2009 Published: April 22, 2009

\section{REFERENCES}

1. S. T. Abu-Orabi, Molecules, 7, 302 (2002).

2. V. V. Rostovtsev, L. G. Green, V. V. Fokin, and K. B. Sharpless, Angew. Chem., Int. Ed., 41, 2596 (2002).

3. Z. M. Li, T. S. Seo, and J. Y. Ju, Tetrahedron Lett., 45, 3143 (2004).

4. S. Punna, J. Kuzelka, Q. Wang, and M. G. Finn, Angew. Chem., Int. Ed., 44, 2215 (2005)

5. G. W. Goodall and W. Hayes, Chem. Soc. Rev., 35, 280 (2006).

6. D. Fournier, R. Hoogenboom, and U. S. Schubert, Chem. Soc. Rev., 36, 1369 (2007).

7. K. E. Johnson, J. A. Lovinger, C. O. Parker, and M. G. Baldwin, J. Polym. Sci., Polym. Lett. Ed., 4, 977 (1966).

8. M. G. Baldwin, K. E. Johnson, J. A. Lovinger, and C. O. Parker, J. Polym. Sci., Polym. Lett. Ed., 5, 803 (1967).

9. Y. H. Hu, Y. H. Luo, L. Q. Wan, H. M. Qi, F. R. Huang, and L. Du, Acta Polym. Sin., 4, 560 (2005).

10. Y. H. Luo, Y. H. Hu, L. Q. Wan, L. Xue, W. Zhou, F. R. Huang, X. N. Shen, H. M. Qi, L. Du, and X. B. Chen, Chem. J. Chin. Univ., 27, 170 (2006).

11. L. Q. Wan, Y. H. Luo, L. Xue, J. J. Tian, Y. H. Hu, H. M. Qi, X. N. Shen, F. R. Huang, L. Du, and X. B. Chen, J. Appl. Polym. Sci., 104, 1038 (2007).

12. J. J. Tian, L. Q. Wan, J. Z. Huang, Y. H. Hu, F. R. Huang, and L. Du, Polym. Adv. Technol., 18, 556 (2007).

13. J. J. Tian, L. Q. Wan, J. Z. Huang, Y. H. Hu, F. R. Huang, and L. Du, Polym. Bull., 60, 457 (2008).

14. J. J. Tian, X. F. Wang, L. Q. Wan, Y. H. Hu, F. R. Huang, and L. Du, High Perform. Polym., In press (2009).

15. C. E. Pawloski, U.S. Patent 3231614 (1966).

16. T. Agag and T. Takeichi, Macromolecules, 34, 7257 (2001).

17. Y. Xiong, F. Y. C. Boey, and S. K. Rath, J. Appl. Polym. Sci., 90, 2229 (2003).

18. L. Xue, L. Q. Wan, Y. H. Hu, X. N. Shen, F. R. Huang, and L. Du, Thermochim. Acta, 448, 147 (2006). 